\title{
An Enterprise Modelling Approach to Team Systems Engineering
}

\author{
Nikita Byer ${ }^{1}$, Richard $\mathrm{H}$ Weston ${ }^{2}$ \\ I Loughborough University, MSI Research Group, Email [n.a.byer@lboro.ac.uk] \\ 2 Loughborough University, MSI Research Group, Email [r.h.weston@lboro.ac.uk]
}

\begin{abstract}
Teams are engineered by dependent processes involving a spectrum of activities commencing with the initial identification of need, extending through to the realisation of that need and in some cases dissolution of the team. A new model of the team systems engineering life cycle is described in this paper which includes four main groupings of activities corresponding to: 'design', 'build', 'operate' and 'maintain' (DBOM) life phases through which a typical team system progresses. The paper illustrates how Enterprise Modelling concepts and the DBOM model can be innovatively deployed in order to systematically capture published knowledge about teams; thereby providing an analytic basis on which teams can be designed, built, operated and maintained. Here EM modelling constructs were used to document and visually represent relatively enduring aspects of tean systems. This paper illustrates the approach by creating a semi-generic model of project teams.
\end{abstract}

\section{INTRODUCTION}

This paper reports on new understandings gained when applying Enterprise Modelling (EM) techniques in a novel way in order to facilitate the systematic reuse of published knowledge about human teams. The prime purpose of so doing is to enable best practice to be achieved when engineering specific cases of this class of complex system in unique manufacturing enterprise (ME) settings. The paper reports on research contributions made during the first author's $\mathrm{PhD}$ study. The full set of research arguments, modelling methodologies proposed and results obtained from case study applications of the proposed modelling methodologies are described in Byer 2004.

Teams and teamworking are topics that have received very significant research attention, primarily by human and behavioural scientists and practitioners. It follows that there exists a massive body of literature on these topics. Teams and teamworking are known to be topics of concern to manufacturing industries worldwide. When a ME gets its teamworking 'right' significant benefits can accrue. Team experts, consultants and academics advance a plethora of theories and techniques, which are derived from the literature on teams and teamworking, to inform and facilitate the successful design, development and implementation of teams. Despite these efforts the literature is populated with examples of teams that fail to produce desired results. Evidently there is a gap between the team approaches 
that are conceived and tested in academia, and deployed by human factors, specialists and consultants, and those that are widely understood and reused within specific industrial settings.

The authors observed a lack of homogeneity within the existing body of literature of teams and teamworking. Although similar theories and concepts are shared, in general these theories and concepts are ill defined with similar terms commonly used to mean significantly different things. This is as might be expected because people are individuals and when attributed to organisational groupings, are known to constitute complex entities that can be viewed from many different perspectives; even then they can only be partially understood. Many related issues (such as emergent behaviours, team culture and motivation) are by nature soft and difficult to quantity. However evidently there is commonality amongst teams (e.g. commonality of purpose, processes, composition, inputs, outputs, performance measures) of similar ilk. The authors also observed (a) significant variation in the perceived importance of teams and teamworking in different MEs and (b) that existing knowledge about teams is currently used in a fragmented, and ad hoc manner, typically driven by an in-house human factors expert or hired teamworking consultant. This again is not surprising because MEs are in general even more complex than is a specific team system and require multi-perspective understandings by people systems which are also concerned about soft and hard issues, which may be of a relatively enduring, or relatively transient nature.

Hence the authors decided to deploy EM techniques to achieve the following objectives, in new and improved ways:

1. Document general understandings about teams and teamworking so as to (a) improve the homogeneity of those understandings, (b) facilitate understanding and interpretation of existing knowledge on teams and (c) encourage the computer-based formulation and reuse of that knowledge.

2. Document semi-generic understandings about different types of team used in MEs, thereby facilitating the capture of reference models of teams and successful scenarios of team systems engineering.

3. Provide generic and semi-generic means of informing, and lending structure, to team working aspects of EE projects; to facilitate decision making about team type selection, team system implementation, enabling team systems operation, and so forth.

\section{REVIEW OF TEAM SYSTEMS LITERATURE}

With aims (i) through (iii) in mind the authors reviewed existing literature on teams and team working. The literature on team systems reported variously on four distinctive system life phases (Byer and Weston, 2004), namely: i) Team System Design; ii) Team System Building; iii) Team System Operation; and iv) Team System Maintenance. Those phases are described in outline in the following.

\subsection{Team System Design}

Teams are commonly designed in a top-down manner so as to implement specified business strategies (Chiesa, 1996 a, b; Dunphy and Bryant, 1999; Schilling and Hill, 1998). Prasad and Akhilesh (2002) state that virtual teams (one of many possible team types) are required to achieve stated objectives and their structures and context have to support these objectives. Thus it is very important to maximise the fit 
between team design and their stated intent. Team system design, they continue, uses the stated objectives of the team to determine the size, team composition and team structures. Prasad and Akhilesh (2002) suggest that proper team design in itself would be of no avail if it does not finally lead to the delivery of top performance. Thus teams need to be structured to achieve maximum effectiveness.

Hence it is observed that team system design requires adequate problem definition to define the problem and to use that definition to determine appropriate team characteristics. Also the characteristics defined should be related to some specific team type (such as a project team or a self-managed team) with stereotypical abilities to meet the problem defined. Hence team design can be viewed as choosing the right team type, i.e. a team type with known characteristics, capacities and capabilities to perform the task(s) at hand within defined constraints.

\subsection{Team System Building}

Team system building has been viewed as the process of selecting a collection of individuals with different needs, backgrounds, and expertise and transforming them into an integrated and effective work unit (Thaimhain and Wilemon, 1987). In such a transformation the goals and energies of individual contributors have to merge so as to support the objectives of the team (Thaimhain and Wilemon, 1987). It follow that effective team system building can be advantageous in adding to the diverse viewpoints and the needed widespread contacts for anticipatory learning (i.e. learning that anticipates change) (McDonald and Keys, 1996).

Partington (1999) states that the quality of the human resources, which make up teams, is a critical determinant of team performance. Castka et al (2003) observations concur with those of many team experts by identifying team composition as being key to top team performance. Oakland (1993) states that no one person has a monopoly of good characteristics, because characteristic behaviours that need to be developed by teams (and within teams) are often contradictory (i.e. good listener vs. fluent communicator).

\subsection{Team System Operation}

Woodcock (1979) stated that any team has two prime areas of concern, namely: i) teamworking development, 'the way the team plays'; and ii) task realisation, 'the direction of individual skills towards a united effort needed to complete tasks and attain goals'. Since Woodcock's publication, many authors have supported his view that teams will concurrently carry out sub-processes concerned with (i) and (ii).

Teamworking Development involves 'taking care of the team members' and is centred on team behaviour, roles, work assignment, communication and so forth (Woodcock, 1979; Stickley, 1993). While task realisation is about 'getting the job done'. Task realisation should lead to attainment of goals and completion of the purpose for which the team was developed (Woodcock, 1979; Stickley, 1993). These two prime areas of concern characterize the actual processes (i.e. activities that need to occur over time) during the team system operation stage

\subsection{Team System Maintenance}

Groesbeck and Van Aken (2001) suggest that achieving effective team design, building and operation represents only a start towards achieving increased competitiveness through teams. Teamworking is the process by which people work together more effectively. Teams are not objects to be installed and left to run 
without further attention or support, rather, team systems must be monitored and supported (Polley \& Ribbens, 1998). This can differentiate team systems markedly from existing forms of technical systems (e.g. machine and software systems).

Given potential difficulties of developing and sustaining effective team system processes, Polley and Ribbens (1998) advocate a 'wellness' approach to deal with chronic and potential team system problems. Wellness has been described as being two interrelated sub-processes, such as: i) Monitoring includes diagnosing past performance and assessing group processes at key checkpoints to assess a team's process health; and ii) Maintenance includes assuring that teams receive the support and coaching needed to develop productive processes for the way they work together and perform core task routines.

\section{FORMULATION OF THE DBOM TEAM SYSTEMS ENGINEERING MODEL}

This research advances the notion that a four-phase DBOM (design, build, operate and maintain) model can represent team systems engineering activities from team 'conception' to team 'grave'.

During team system design, the $\mathrm{D}$ phase, information about the objectives of the team is deployed. Here information about the task and task characteristics is interpreted to determine needed team characteristics, such as its composition, size, structure and so on. Team system building, the B phase, involves constructing the team system by selecting and bringing together individuals with appropriate skills, knowledge and expertise. Research of the authors of this paper has shown that skillrequirements of teams can be usefully determined from the task definition and task characteristics (Byer 2004). Both functional roles and team roles should be allocated during the team system building phase. Team system operation, the $O$ phase, concerns two distinct but related sub-processes, namely: i) teamworking development and ii) task realisation. Whereas team system maintenance, the $M$ phase, is characterised by two main concerns, i) monitoring and ii) maintaining team system processes.

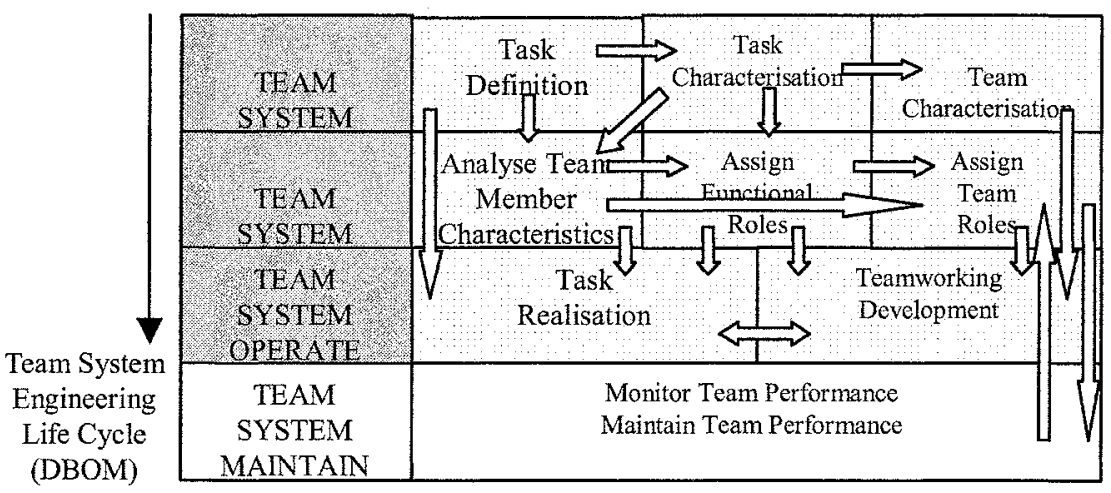

Figure 1. The DBOM Life Phases of Team Systems

Figure 1 was constructed to illustrate the DBOM phases described above. It groups the team system engineering activities that must be performed from identifying task requirements, through designing the team and allocating resources, to achieving teamworking development and realising the task, and terminating with completion 
of the task or dissolution of the team. It also illustrates relationships and dependencies between these activity groupings. For example it was determined that team system design comprises three main activities, namely: task definition, task characterisation and team characterisation, which are interrelated. The task characterisation activity receives inputs from the task definition activity, and task characteristics are used to inform the determination of team characteristics.

Information contained in the task definition and about task characteristics is used to inform decisions made about needed member characteristics during the team system build phase. It follows that DBOM engineering activities are inter-related and impact collectively on team system effectiveness.

\section{DECOMPOSITION OF THE DBOM TEAM SYSTEM ENGINEERING PHASES}

During the process of designing a team system, task descriptions and task requirements are referenced as they provide details pertaining to: the team's purpose; time required for task completion; leadership requirements; team size and team composition (in terms of functional skills). Figure 2 illustrates team system design in terms of its primary input events and output results. It also lists its key subprocesses.

EVENT INPUTS

RESULT OUPUTS

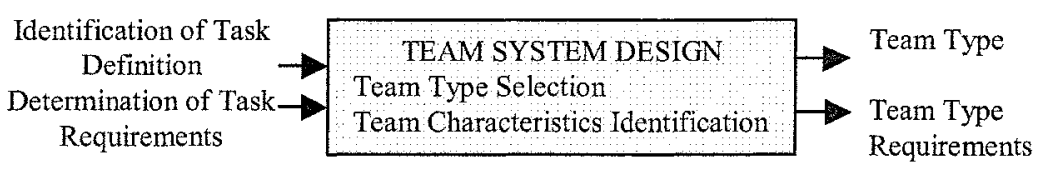

Figure 2. Graphical Model of Team System Design

Team system building is illustrated by figure 3 . This constitutes a process of building the team by: selecting the most appropriate team members based on their technical competences; allocating team roles to selected members centred on their behavioural competences; providing the team with an organising 'structure'; and finally releasing the team to achieve the task. Thus it was observed that the process of team system building can be further decomposed into four sub-processes, namely: member selection; role allocation; structure development and team release. During the team system building process, team member selection is determined with reference to the functional skills required and matching this to the technical skills,

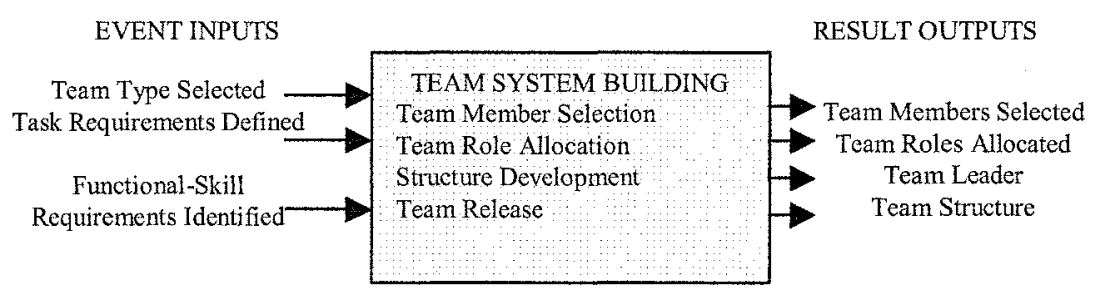

Figure 3. Graphical Model of Team System Building

experience and education of candidate team members. Once selected, team members are assigned team roles. The team leader is chosen and the team structure can 
subsequently be developed. Figure 4 depicts the elements of the team system operation process. This also identifies sub-processes, event inputs and output results. Team system operation, the $O$ phase, is centred on teamworking development and task realisation. Team System Operation is concerned with how the team develops from a group of individuals to an efficient functioning unit while successfully realising the task assigned and delivering the task goals.

Team system maintenance incorporates two interrelated processes: monitoring and maintenance. In this paper the authors emphasis the importance of the team system monitoring sub-process, as a vital source of information pertaining to the performance and effectiveness of the $D, B$ and $O$ life phases. Team system monitoring naturally provides feedback with regard to team system effectiveness. In the first instance it can function to provide feedback with respect to teamworking development and task realisation performance. Secondly, it can provide feedback regarding the suitability of the team members selected, team members roles allocated and the structure developed and deployed. Finally it can feed back quality (i.e. fitness for purpose) about the type of team selected. Figure 5 shows a graphical decomposition of the team system monitoring sub-process.

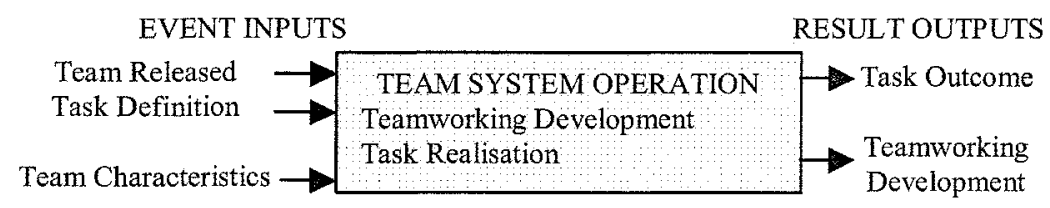

Figure 4. Graphical Model of Team System Operation

In general it is assumed that the team system maintenance sub-process can utilise feedback information generated by the team system monitoring process in a wide variety of ways. For example, maintenance sub-processes might analyse, reflect on, predict and improve the performance of (1) operational teams and team members or (2) future teams (when used to achieve similar tasks or when similar team types are to be used to realise new tasks).

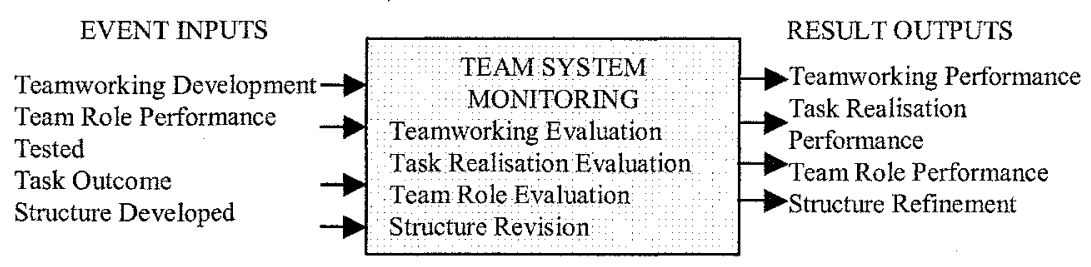

Figure 5. Team System Monitoring Sub-Processes, Event Inputs and Results Outputs

\section{FORMALISATION OF TEAM SYSTEMS ENGINEERING KNOWLEDGE}

The CIMOSA reference framework was designed to structure many aspects of enterprise engineering projects (Kosanke, 1996). CIMOSA lends structure to the activities of enterprise modellers as they seek to generate models with different levels of generality, i.e. generic, partial or particular enterprise models. Monfared $e t$ al (2002) states that users can generate enterprise models at any of these three levels 
of generality and that other models at different levels of generality can be derived by referencing captured models, thereby reducing the modelling effort required.

In this study it was considered appropriate to develop partial models of team systems, and the processes and sub-processes needed to engineer teams during their lifetime. A particular focus of attention was to be placed on semi-generic application domains in which enterprise teams are commonly deployed. One such domain analysed concerned cases where project teams are assigned a new task. With respect to this domain it was decided that partial models could usefully be captured formally by using the following representational forms (Byer, 2004):

- Overall context diagram for the 'engineer new project team system' domain

- Overall interaction diagram for the 'engineer new project team system' domain

- Context diagram for 'team system building' (B phase of DBOM)

- Interaction diagram for 'team system building'

- Structure diagrams for 'team role allocation', 'team structure development' and 'team release' (sub-processes of team system building)

- Context diagram for 'team system operation' (O phase of DBOM)

- Interaction diagram for 'team system operation'

- Structure diagrams for 'task realisation', 'teamworking development' and 'team operation progression' (sub-processes of team system operation)

- Context diagram for 'team system monitoring' (M phase of DBOM)

- Interaction diagram for 'team system monitoring'

- Structure diagram for 'team role performance', 'teamworking development performance' and 'structure refinement' (sub-process of team system monitoring)

Only the first four of these representational forms are illustrated in this paper.

\subsection{Overall Context Diagram for "Engineer New Project Team System"}

Figure 6 depicts the overall context diagram for the target "engineer new project team system' domain process. This shows that engineering a new project team system involves interactions between activities that 'belong to' the 'design team system', 'build team system', 'operate team system', and 'monitor team system' domains. In this case the 'design team system' domain was designated a nonCIMOSA domain and was not considered in detail within the authors' research.

\subsection{Overall Interaction Diagram for "Engineer New Project Team System"}

Next it was considered necessary to formulate a detailed analysis of elements that constitute the complete 'engineer new project team system' process. To accomplish this existing information about team systems that was coded into the ad hoc graphical models described in previous sections of this paper, was reformatted in the form of a high-level CIMOSA conformant interaction diagram so as to characterise primary interactions in the 'engineer new project team system' domain, see figure 7. This figure documents the primary flows of information, human resources and physical resources between the sub-domains of the 'engineer new project team system' domain.

Detailed descriptions of task requirements, task goals and teamworking information are passed from the 'team system building' domain process (designated DP 1) to 'team system operation' domain process (designated DP 2). Through the team systems life cycle this information can include task definitions; task 
requirements; task goals; teamworking goals; initial team operating procedures; initial organisational structures; and constraints and boundaries. Physical resources such as task descriptions; drawings and other types of technical specifications; machines; equipment; and computer software to support the transfer and deployment of this information. A team developer is also designated responsibility for regularly monitoring team system operation.

The 'team system operation' domain process (DP 2) generates extensive information for deployment by the 'team system building' domain process (DP 1). Teambuilding proposals and recommendations are typically derived from a number of project team meetings. Each change request from the 'team system operation' domain process (DP 2) requires the 'team system building' domain process (DP 1) to respond with change assessment information. Information about 'team system operation' is derived with respect to task realisation and teamworking development outcomes.

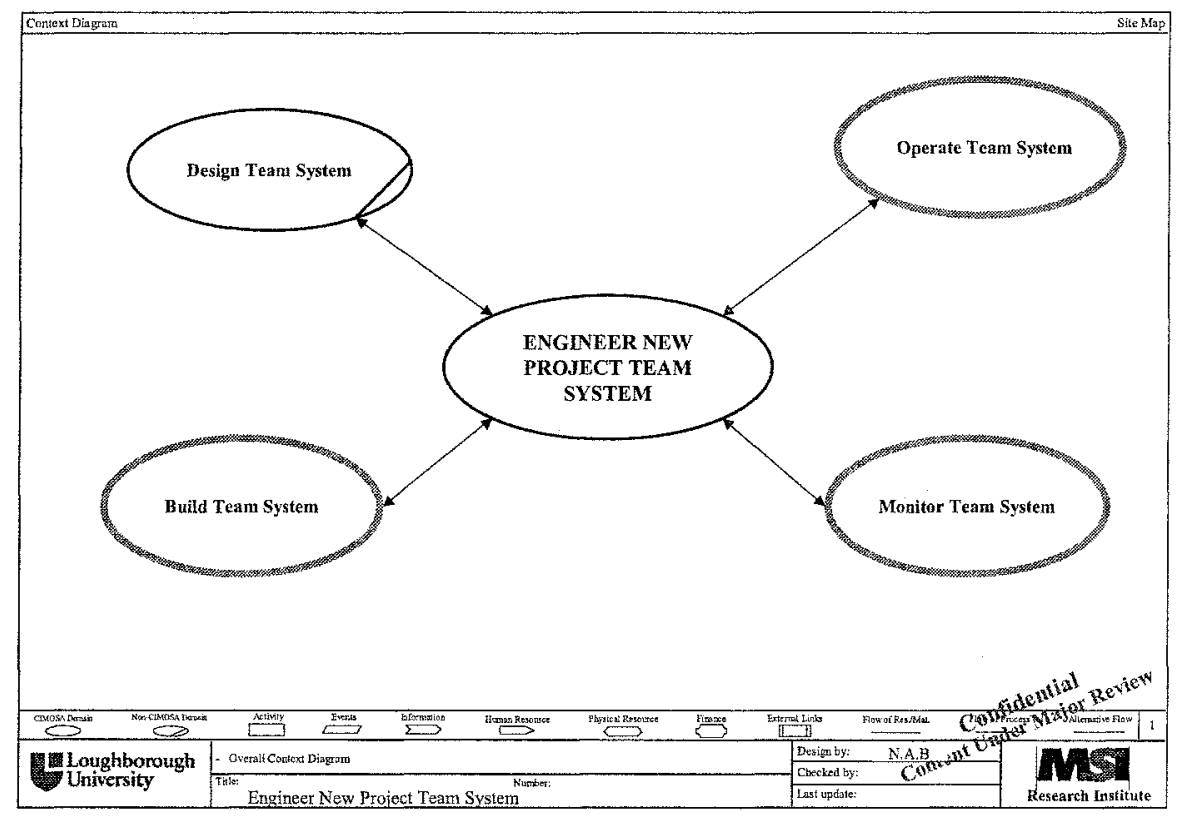

Figure 6. Overall Context Diagram for 'Engineer New Project Team System'

\subsection{Context Diagram for "Team System Building"}

Figure 8 illustrates the context diagram developed to formally represent the "team system building' domain. This CIMOSA domain can be sub-divided into four constituent CIMOSA sub-processes, namely: 'team member selection'; 'team role allocation'; 'structure development'; and 'team implementation'. The reader should note that the analysis presented in this paper focuses predominantly on team aspects rather than the task aspects of the team system

\subsection{Interaction Diagram, Team System Building}

Initially this domain was considered from a broad perspective; hence an interaction diagram was created for the 'team system building' domain with the aim of visually identifying how its four sub-processes play a role in the overall 'team system 
building' domain process (DP1). As illustrated by figure 9, it can be observed that this domain can be decomposed into four sub-domain processes, namely: i) Team Member Selection (designated DP11); ii) Team Role Allocation (DP12); iii) Structure Development (DP13); and iv) Team Release (DP14).

Error! Objects cannot be created from editing field codes. Figure 7. High Level Interaction Diagram for "Engineer New Project Team System"

This figure shows that information concerning task definition and task requirements from the non-CIMOSA domain 'team system design' constitutes a key input of the 'team member selection' (DP11) domain process. Physical outputs from this domain were observed to include 'member's technical competence lists', which is passed both to the 'team role allocation' domain process (DP12) and 'team structure development' domain process (DP13).

Also observed was that the team release process (DP14) should receive information on task operating instructions, teamworking instructions, members' team role preference and team role allocation. Further this domain (DP14) receives information, physical resources and human resources from all three of the other domains and is required to use this information to facilitate the progression of the team system, from a group of individuals to a unit working towards a common goal.

\section{CONCLUSION AND FURTHER WORK}

This paper explains that teams can be viewed as being complex systems with associated life phases and processes that characterise them in life cycle engineering terms. Literature on team systems was reviewed and organised with reference to four phases of a newly proposed generic model of team systems engineering, comprising team system design; team system building; team system operation; and team system maintenance. It was presumed that a formal characterisation and representation of existing literature on teams could be achieved using EM concepts and that resultant enterprise models could promote an effective reuse of that knowledge. The life phases observed were distinctive in terms of the events, activities and processes that occur. Further, these DBOM phases encompass groupings of activities performed from initial identification of task definitions and requirements through designing the team, allocating resources, achieving teamworking development, realising the task and terminating at the completion of the task or dissolution of the team. 


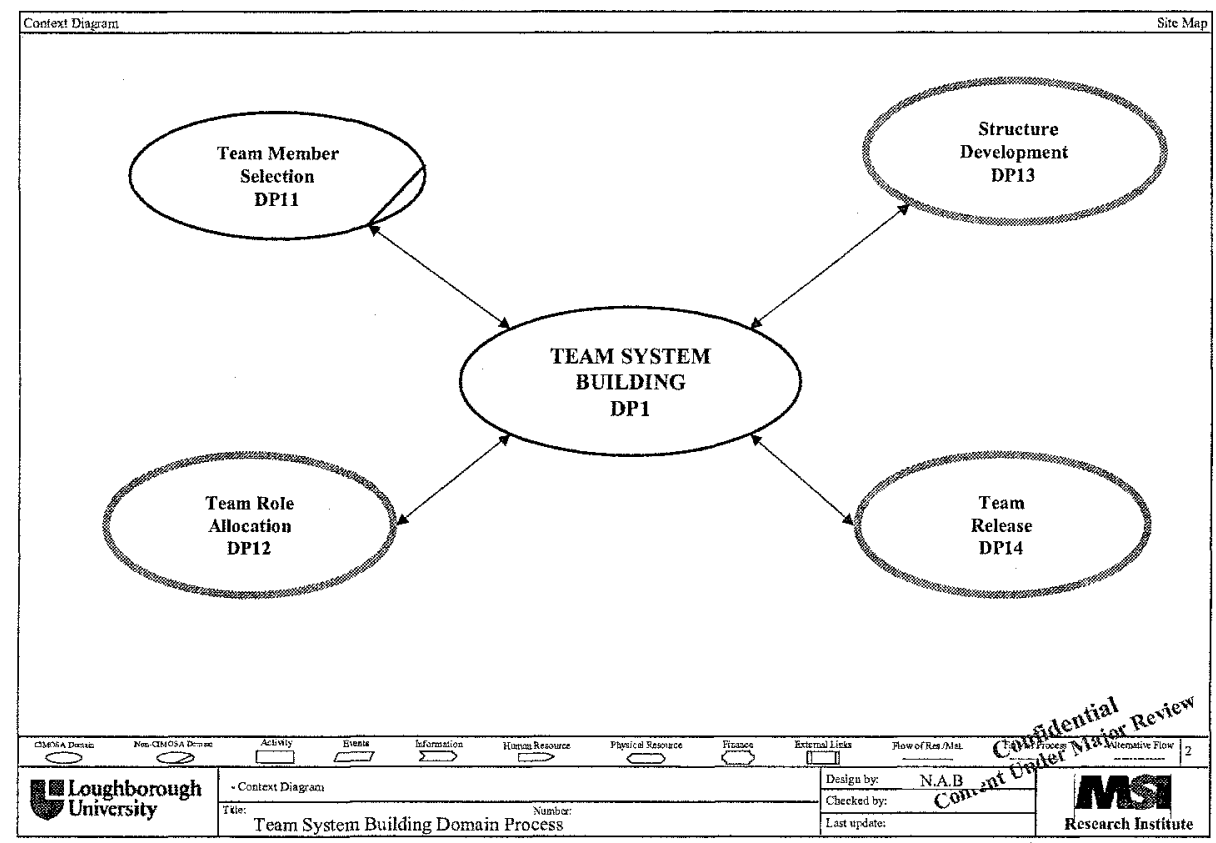

Figure 8. Context Diagram for 'Team System Building' Domain

CIMOSA diagramming templates were used to capture, represent and formalise static (relatively enduring) views of team system processes. It was observed that best-in-class EM techniques could usefully facilitate the capture and reuse of both semi-generic and particular models of team system engineering. This paper shows in outline how CIMOSA diagramming notations were deployed to formally document various semi-generic perspectives on team systems engineering related to the 'project engineering' team class.

It was envisaged that semi-generic and particular models of teams created using EM concepts can be reused for a variety of purposes; such as to inform the life cycle engineering of specific project teams that have been assigned a new task, or to provide an action plan for design, operation and maintenance (as a template) for modelling many, possibly most, types of teams used in industry.

It was observed that many domain models could usefully be created to inform the lifecycle engineering of common team types found in MEs. Here it was envisaged that semi-generic DBOM models could be populated and used to inform the creation and reuse of particular DBOM models which could be related to models of specific ME processes. Thereby it was envisaged that EE practice could be informed and advanced by using EM to organising and facilitating the reuse of the massive body of existing knowledge on teams. However, it is understood that much work remains to determine all needed semi-generic models of team types and to populate and validate an industry-wide use of those models. Also it was observed that not all aspects of team systems engineering can be formalised and enabled via EM. Some softer aspects of team systems engineering need to remain essentially ad hoc and human centred. 
The authors consider their DBOM proposal to be of potentially high significance because it provide a semi-formal definition of terms needed to facilitate an interchange of conceptual ideas and proposals between human scientists and ME practitioners. EM and simulation modelling can facilitate an organised and explicit reuse of human systems knowledge and can explicitly articulate ME needs in terms understood by human scientists.

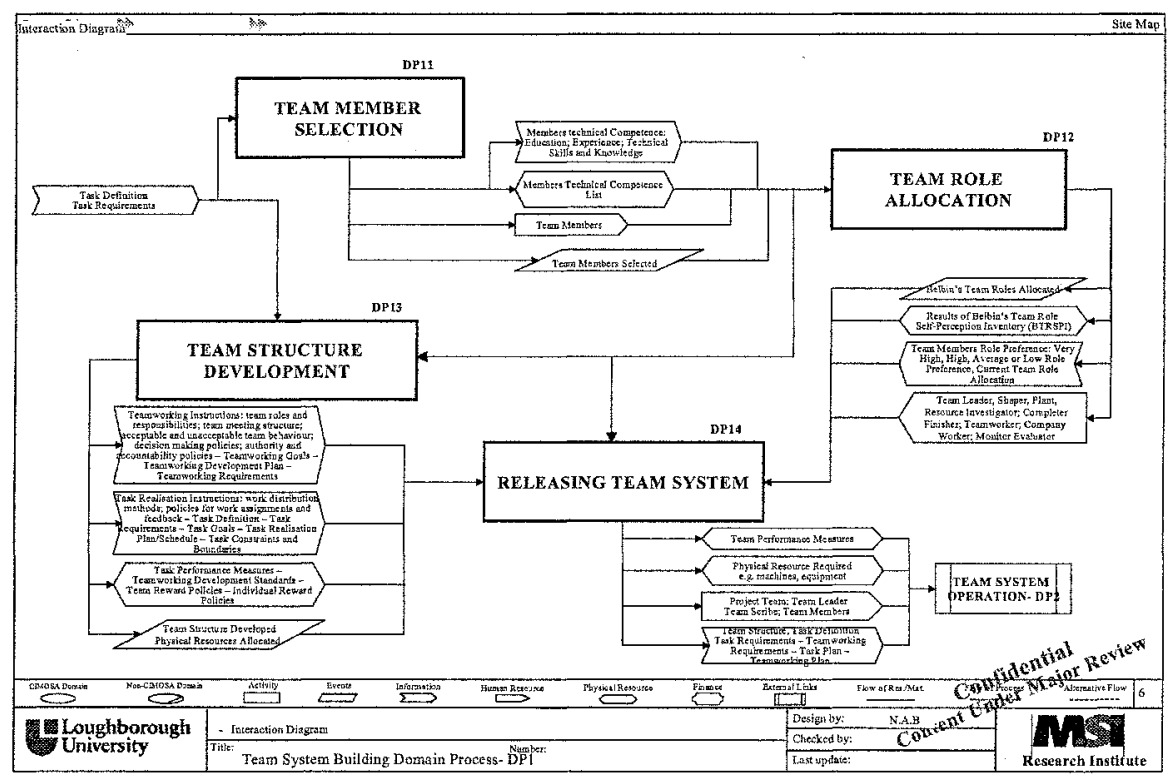

Figure 9. Interaction Diagram for 'Team System Building' Domain Process

\section{REFERENCES}

Ajaefobi, J.O. (2004) Human systems modelling in support of enhanced process realisation. PhD Thesis, Loughborough University, Leics., UK.

Byer, N. A. (2004) Team Systems Engineering and the Role of Enterprise Modelling Technologies. $\mathrm{PhD}$ Thesis, Loughborough University

Byer, N.A., Weston, R.H. (2004) A Life Cycle Model of Team System Engineering. In Proceedings of the Institute of Mechanical Engineers, Part B, Journal of Engineering Manufacture, Submitted in 2004.

Castka, P., Bamber, C. J. and Sharp, J. M. (2003) Measuring Teamwork Culture: the use of a modified EFQM model. J. of Management Development, 22(2), 149-170

Chiesa, V. (1996) Managing the Internationalisation of R\&D Activities. In IEEE Transactions on Engineering Management, 43(1)

Chiesa, V. (1996) Strategies for Global R\&D. Research Technology Management, $39(5)$

Dunphy, D., Bryant, B. (1999) Teams: Panaceas or Prescriptions for Improved Performance? Human Relations, 49(5), 677 - 699

Groesbeck, R., Van Aken, E.M. (2001) Enabling Team Wellness: Monitoring and Maintaining Teams After Start-up. Team Performance Management: An International Journal, 7(1/2), $11-20$ 
Kosanke, K. (1996) Process Oriented Presentation of Modelling Methodologies. In Modelling Methodologies and Enterprise Integration, P. Bernus, L. Nemes (Eds) London : Chapman and Hall

McDonald, J.M., Keys, J.B. (1996) The Seven Deadly Sins of Teambuilding. An International Journal of Team Performance Management, 2(2), 19-26

Monfared, R.P., West, A.A., Harrison, R., Weston, R.H. (2002) An Implementation of the Business Process Modelling Approach in the Automotive Industry. In Proceedings of the Institute of Mechanical Engineers, Part B, Journal of Engineering Manufacture, 216(B11), 1413-1427

Oakland, J. (1993) Total Quality Management: the Route to Improving Performance. Oxford: Butterworth-Heinemann

Partington, D. and Harris, H. (1999) Team Role Balance and Team Performance: an empirical study. The Journal of Management, 18(8), 694-705

Polley, D., Ribbens, B. (1998) Sustaining self-managed teams: a process approach to team wellness. Team Performance Management, 4(1), 3-21

Prasad, K., Akhilesh, K.B., (2002). Global Virtual Teams: What Impacts Their Design and Performance. Team performance Management: An International Journal, 8(5/6), 102-112

Schilling,M.A., Hill,C.W.(1998) Managing the New Product Development Process: Strategic Imperatives. IEEE Engineering Management Review, Winter, 55-68

Stickley, A. (1993) Selection and Development of Effective Teams within Design Function Deployment. In Quality and Its Application Conference at University of Newcastle Upon Tyne

Thaimhain,H.J., Wilemon,D.L. (1987) Building High Performing Engineering Project Teams. IEE Transactions on Engineering Management, 34(3), 130-137

Woodcock, M. (1979) Team Development Manual. Farnborough, UK: Gower Publishing 